\title{
LA COLISIÓN CULTURAL ENTRE DOS VISIONES: JUSTICIA INDÍGENA Y DERECHO \\ ESTATAL ${ }^{*}$
}

\author{
CULTURAL COLLISION AMONG TWO \\ VIEWS: INDIGENOUS JUSTICE AN D \\ PUBLIC LAW.
}

\section{A COLISÃO CULTURAL ENTRE DUAS VISÕES: A JUSTIÇA INDÍGENA E A LEI ESTADUAL}

\author{
Nancy Solano de Jinete ${ }^{a}$ \\ nancy_sol@hotmail.com \\ Germán Humberto Padilla Ospina \\ germanhpadilla@gmail.com \\ Fecha de recepción: 12 de Junio 2014 \\ Fecha de revisión:2 de Julio 2014 \\ Fecha de aceptación: 15 de Julio 2014
}

\section{RESUMEN}

El problema que suscita el interés de la presente investigación tiene un eje particular: El choque entre la visión de mundo de una mayoría con la visión de mundo de una minoría. Suscitada por los límites impuestos por una cosmovisión mayoritaria representada por la dogmática de los Derechos Humanos, conquista de la cultura occidental, la cual ha sido aceptada de manera global, por la gran mayoría de los países del planeta. La otra cosmovisión, la "minoritaria", es la que se encuentra representada por el Derecho Propio de los pueblos indígenas.

* El presente artículo de investigación científica es producto del trabajo de investigación titulado "Tensiones entre los Derechos Humanos y el Derecho Indígena, bajo la Óptica Jurisprudencial", desarrollado por el grupo de investigación Análisis Jurídico de la facultad de derecho de la Universidad Colegio Mayor de Cundinamarca, en el cual se realizó un estudio jurisprudencial y acucioso de manera transversal relacionado con las decisiones judiciales de las comunidades indígenas que a juicio de la Corte Constitucional vulneran o no derechos fundamentales. También se complementó esta investigación con el estudio de un trabajo de campo realizado dentro de la comunidad Wayuu en los rancherías de Palasimana, La Loma e Irrachon, donde se establece que no obstante la preponderancia del derecho del blanco o "civilizado", sobre las comunidades indígenas y en especial la Wayuu, prevalecen en ellas la aplicación del derecho propio indígena, con las observancias y conclusiones que se anotan al final de la investigación.

Reunión de palabreros en Uribia. Los registros fotográficos que aparecen en la presente investigación, fueron tomados por los investigadores durante el desarrollo del trabajo de campo.

a. Abogada de la Universidad Libre. Magister en Educación Superior Con Énfasis En Investigación de la Universidad Pedagógica Nacional. Docente de planta de tiempo 
Las tensiones suscitadas entre estas dos visiones del derecho emergen por los límites establecidos por la constitución y la ley a la autonomía jurisdiccional de los pueblos indígenas.

En la presente investigación se desarrolló un análisis de las algunas sentencias proferidas por la Corte Constitucional donde se evidencia este tipo de tensiones. Para complementar la descripción del problema, se realizó un trabajo de campo en tres comunidades de la Guajira, con el objetivo de tener un acercamiento a sus normas de control social y evidenciar cómo estas en alguna forma traspasan los límites establecidos por los derechos fundamentales consagrados en la Constitución política de 1991.

Como objetivo general se propuso determinar los conflictos existentes entre los postulados de los Derechos Humanos con las tradiciones jurídicas de las comunidades indígenas bajo un análisis jurisprudencial. Para hacer realizable el propósito de la investigación, fue necesario plantear los siguientes objetivos específicos: la realización de un análisis jurisprudencial acerca de las decisiones de las comunidades indígenas que vulneran o no derechos fundamentales; aunado a la elaboración de un trabajo de campo en la comunidad indígena Wayuu, en las rancherías La Loma, Irrachón y Palashimana, a fin de determinar la aplicación de su derecho propio dentro de su territorio.

Respecto a la metodología empleada, inicialmente se parte de una recopilación

completo de la Facultad de Derecho de La Universidad Colegio Mayor de Cundinamarca. Orienta la cátedra de Seminario de Investigación y la electiva de Derechos Humanos. Líder del grupo de investigación análisis jurídico, reconocido por Colciencias. Adscrita al Centro de Investigaciones Socio-Jurídicas, y con investigaciones culminadas en el ámbito jurídico y pedagógico y conocimiento especializado en derechos autorales. Ha publicado los siguientes libros: Metodología de la Investigación Socio jurídica. Derechos de autor en el ámbito universitario. Pedagogía del derecho en el siglo XXI. La Prejudicialidad en el sistema jurídico colombiano. La eficacia de la Corte Penal I/Nal ante la vulnetraciòn de los D.D.H.H.

b. Licenciado en Filología e Idiomas con énfasis en alemán de la Universidad Nacional. Abogado de la Universidad Colegio Mayor de Cundinamarca. Especialista en Filosofía del Derecho y Teoría Jurídica de la Universidad Libre y candidato a Magister en Filosofía del Derecho de la misma Universidad. Miembro del grupo de investigación Análisis Jurídico, reconocido por Colciencias. Actualmente se desempeña como investigador auxiliar de la facultad de derecho de la Universidad Colegio Mayor de Cundinamarca y como abogado en el sector financiero. Sus campos de investigación cubren los temas de Pluralismo Jurídico y Derechos Humanos. documental basada en teorías y jurisprudencias para puntualizar en la casuística propuesta en el trabajo de campo en las poblaciones indígenas y así, establecer las tensiones que surgen entre la justicia ordinaria y el derecho propio indígena, en el estudio jurisprudencial y en el trabajo de campo.

\section{PALABRAS CLAVES}

Derecho propio indígena - Multiculturalismo - Plurietnico - Tensiones - Derechos Humanos - Línea Jurisprudencial - Expresión Cultural - Diversidad Étnica - Límites a la Jurisdicción Indígena - Justicia Wayuu.

\section{ABSTRACT}

The problem that attracts the interest on this research has a particular axis: The crash between the world view of a majority with the worldview of a minority. Raised by the limits imposed by a majority represented by the dogmatic worldview of Human Rights, conquest of Western culture, which has been accepted globally, for the vast majority of countries on the planet. The other worldview, the "minority" is what is represented by the Proper Law of Indigenous People. Tensions raised between these two visions of law emerge by the limits set by the constitution and the law to the jurisdictional autonomy of indigenous people.

In this research the development of an analysis of some judgments issued by the Constitutional Court where such tensions evidence. To complete the description of the problem, a field study was conducted in three communities in the Guajira, in order to become acquainted with their rules of social control and show how these are in any way beyond the limits set by the Fundamental Rights enshrined in the 1991 Constitution.

As a general purpose, was to set out the existing conflicts among the postulates on Human Rights with juridical traditions of indigenous communities under a jurisprudential analysis. To achieve the aim of the investigation it was necessary to consider the following specific objectives: to carry out a jurisprudential analysis about the decisions of indigenous communities that violate or not Fundamental Rights; combined with a field work in the Wayuu indigenous community, in the small villages of La Loma, 
Irrachón y Palashimana, to define the application of their own right inside their territory.

In relation to the methodology used, initially departs from a documentary review based on theories and precedents to specify in the casuistry recommended in the field work in indigenous communities, in such a way to establish the tensions that raise between ordinary justice and the indigenous Proper Law, in the jurisprudential study and in the field work.

\section{KEYWORDS}

Multiculturalism - - Indian multiethnic own right - Tension - Human Rights - Jurisprudencial Line - Cultural Expression - Wayuu Justice.

\section{RESUMO}

O problema que desperta o interesse desta pesquisa tem um eixo específico: o embate entre a visão de mundo de uma maioria comum e a visão de mundo de uma minoria. Suscitada pelos limites impostos por uma cosmovisão maioritária representada pela dogmática dos direitos humanos, conquista da cultura ocidental, aceita globalmente pela grande maioria dos países do planeta. A outra visão de mundo, a "minoria", constitui-se no próprio direito dos povos indígenas.

As tensões originadas destas duas visões do Direito emergem pelos limites fixados pela Constituição e pela lei da autonomia jurisdicional dos povos indígenas.

A presente pesquisa analisou algumas sentenças proferidas pelo Tribunal Constitucional em que há evidência deste tipo de tensão. Para complementar a descrição do problema, um trabalho de campo foi realizado em três comunidades de La Guajira, a fim de se obter uma abordagem das suas regras de controle social e evidenciar como estas, de alguma forma, atravessam os limites dos direitos fundamentais consagrados na Constituição Política de 1991.

O objetivo geral foi o de determinar os conflitos entre os princípios dos direitos humanos com as tradições jurídicas de comunidades indígenas, sob uma análise jurisprudencial. Para viabilizar a finalidade da investigação, foi necessário definir os seguintes objetivos específicos: a realização de uma análise jurisprudencial das decisões das comunidades indígenas que violem os direitos fundamentais ou não; juntamente com o desenvolvimento de um trabalho de campo na comunidade indígena Wayuu, nas aldeias La Loma, Irrachón e Palashimana, para determinar a aplicação da sua própria lei no seu território.

Quanto à metodologia, inicialmente foi feita uma compilação documental com base em teorias e jurisprudência, para apontar no trabalho de campo, na proposta casuística, nas populações indígenas e, assim, estabelecer as tensões que surgem entre a justiça comum e o próprio direito indígena, no estudo de jurisprudência e no trabalho de campo.

\section{PALAVRAS-CHAVE}

Direito próprio indígena; multiculturalismo; multiétnica; tensão; direitos humanos; linha jurisprudencial; expressão cultural; diversidade étnica; limites sobre jurisdição indígena; justiça Wayuu. 


\section{INTRODUCCIÓN}

\section{(Registro fotográfico 1) ${ }^{1}$}

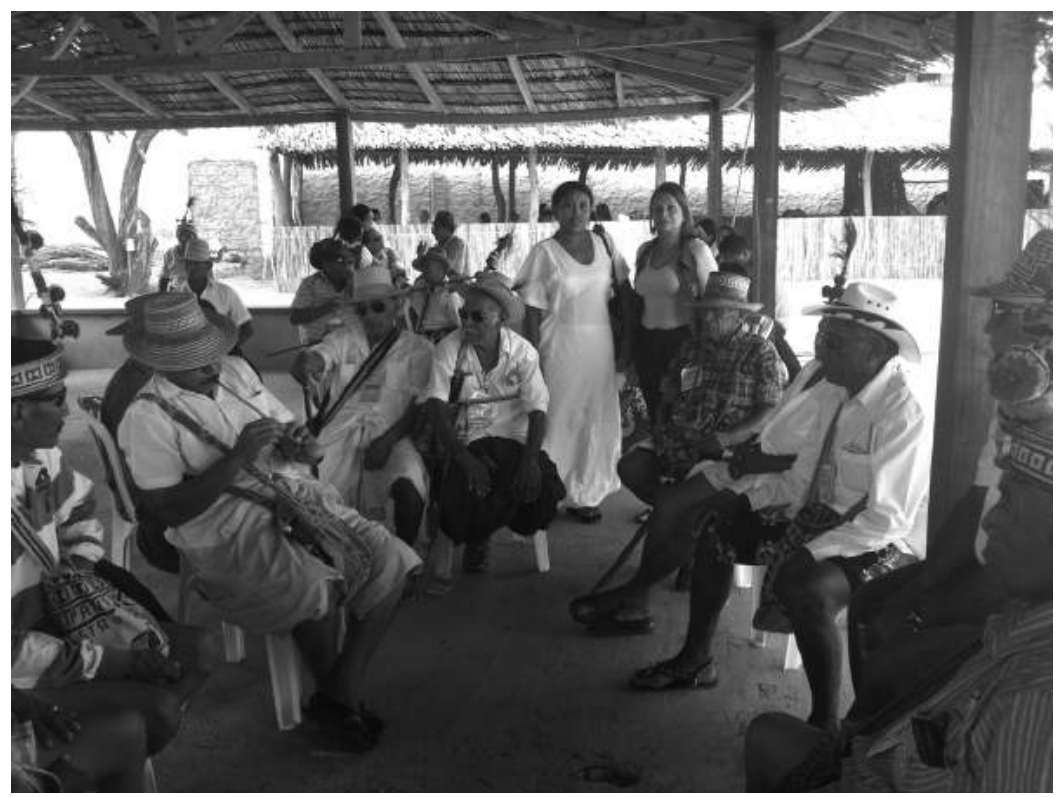

1 Reunión de palabreros en Uribia. Los registros fotográficos que aparecen en la presente investigación, fueron tomados por los investigadores durante el desarrollo del trabajo de campo.

Por cada grupo indígena existe un sistema de derecho; un conjunto de normas que se adecuan al modo de concebir la realidad, de acuerdo a sus esquemas de pensamiento. El derecho como expresión cultural, ha sido reconocido y protegido por las leyes fundamentales de la República. La existencia del otro es tolerada, dejando atrás los intentos de una actividad civilizadora, difundida desde los tiempos del descubrimiento.

Aquel derecho, el desconocido, el no difundido, el ignorado, también converge simultáneamente dentro del territorio nacional. Hace parte de la diversidad, la multiplicidad de cosmovisiones, de otras formas de concebir los fenómenos que giran alrededor de nuestro entorno, otra forma de percibir la realidad, de interpretarla, valorarla y sentirla.

La Constitución Política de 1991 reconoció el campo de la diversidad. Después de largos años de desconocimiento del pluralismo y de la riqueza cultural de nuestra nación, se comenzaron a proteger las múltiples cosmovisiones y desarrollos culturales propios.

El derecho corresponde a una de esas manifestaciones culturales que está protegida por la Constitución, la cual ha reconocido la autonomía jurídica de los pueblos indígenas, al establecer que estos podrán ejercer funciones jurisdiccionales de conformidad con sus propios usos y costumbres. (Artículo 246 de la Constitución Política de Colombia).

A pesar de este reconocimiento al derecho propio indígena, aunado al derecho a la autonomía otorgada a las autoridades tradicionales para su ejercicio dentro de sus territorios, la Carta Magna ha limitado dicho ejercicio, rechazando todos aquellos actos que en nombre de la autonomía indígena se ejerzan en contra de la constitución y las leyes de la República. Es aquí donde los postulados básicos de los derechos humanos, empiezan a chocar con las prácticas ancestrales de los grupos indígenas al momento de administrar justicia.

De esta manera formulamos el siguiente problema de Investigación: los D.D.H.H. y los postulados de la Constitución Política de Colombia no han sido suficientes para el total y real reconocimiento de los derechos propios de los indígenas en Colombia.

Por lo tanto está investigación responderá a dos importantes preguntas: Primera, ¿Cuáles 
son las tensiones generadas por el choque de la visión jurídica mayoritaria representada por los derechos humanos y la visión jurídica minoritaria representado por el propio derecho indígena? Segunda, ¿Cuál es el tratamiento jurisprudencial de la Corte constitucional al momento de dirimir las tensiones suscitadas entre los D.D. H.H. y el Derecho propio indígena?

\section{METODOLOGÍA DEL PROYECTO}

Respecto a la metodología empleada, inicialmente se parte de una recopilación documental basada en teorías y jurisprudencias para puntualizar en la casuística propuesta en el trabajo de campo en las poblaciones indígenas y así, establecer las tensiones que surgen entre la justicia ordinaria y el derecho propio indígena, en el estudio jurisprudencial y en el trabajo de campo.

Está investigación se realiza con el grupo de investigación denominado Análisis Jurídico, reconocido por COLCIENCIAS en categoría D. El proyecto de investigación por su envergadura Jurídica Política y Cultural se enmarca en las dos líneas institucionales establecidas por la Facultad de Derecho de la Universidad Colegio Mayor de Cundinamarca denominadas: Derecho, Sociedad y Cultura Jurídica y Derecho penal y estándares internacionales.

\section{La Constitución Política y la Autonomía Jurisdiccional Indígena}

La consagración de la autonomía legislativa y jurisdiccional establecida no es total. Sus límites reposan en la constitución y en la ley. Estos límites son los que han generado una variedad de conflictos jurídicos interpretativos cuando el Juez se enfrenta con el choque de varios principios constitucionales que podrían encontrarse en un mismo rango de importancia.

Por ejemplo, si la utilización del fuete o del cepo por parte de la comunidad Páez, utilizada como castigo simbólico y enraizada en su concepción del mundo, manifestación clara del principio de la diversidad étnica y cultural, viola el derecho fundamental a la vida o a la integridad física de la persona que recibe el castigo.(CConst, T 523/97 C. Gaviria); o si la expulsión de un miembro de la comunidad, del resguardo indígena donde habita, viola la prohibición del destierro establecida en la constitución.(CConst T 254/94. E. Cifuentes).

Para citar otro caso, el Juez se ha enfrentado con el problema de establecer si la expulsión de los miembros de una comunidad evangélica de su resguardo, y la sanción a un grupo de indígenas que profesan la religión evangélica, viola el principio de la libertad de cultos. (CConst SU 510 /98).

Tales embates jurídicos han sido promovidos gracias a la interposición de la acción de tutela por los mismos miembros de las comunidades indígenas. Su resolución ha permitido a la Corte Constitucional desarrollar una línea jurisprudencial sentando precedentes importantes sobre los principios de interpretación, basados en el concepto de ponderación de derechos, que le permiten al juez de la república guiar su razonamiento a la hora de promulgar un fallo donde se involucre este conflicto de derechos.

\section{ANÁLISIS JURISPRUDENCIAL}

En este apartado nos centraremos en el análisis realizado de las sentencias proferidas por la Corte Constitucional, en donde se suscitan las tensiones entre el derecho estatal y el indígena, debido inicialmente a la imposición de límites.

Hemos adoptado la metodología de las líneas jurisprudenciales formulando el siguiente problema jurídico: ¿Qué tipo de decisiones normativas proferidas por una comunidad indígena vulneran, o no, Derechos Fundamentales, a juicio de la Corte Constitucional?

Para ello procedernos a explicar el planteamiento metodológico y posteriormente ilustrar los apartados más importantes de algunas de estas sentencias, en donde emergen las tensiones de dos visiones particulares del derecho.

La finalidad de adoptar una metodología para el análisis jurisprudencial tiene como objeto, de una parte, centrar nuestro trabajo en los aspectos más relevantes de las jurisprudencias constitucionales que permitan establecer las tensiones suscitadas entre los derechos humanos y el derecho propio indígena. Se busca encontrar un orden, una forma con la que no lleguemos a 
dispersiones al momento del desarrollo analítico propuesto.

Dado el alcance y la importancia que ha tenido el concepto de precedente jurisprudencial en nuestro país, pretendemos así mismo realizar una línea jurisprudencial, la cual, tomada como propuesta metodológica, nos sirve como herramienta para establecer un problema jurídico que encabece la línea.

Para está metodología, basada en los conceptos de líneas jurisprudenciales, tomamos como referencia apartes de la propuesta del profesor Diego López Medina, en su libro El Derecho de los Jueces.
No pretendemos hacer un uso estricto de lo planteado por el doctor López, queremos dejar algo de flexibilidad al estudio de las jurisprudencias abordadas. Es claro que esta investigación no se centra en un estudio de líneas jurisprudenciales de acuerdo con lo establecido por este autor. Se trata de una herramienta metodológica, más no del ejercicio de su aplicación estricta.

En "el Derecho de los Jueces" se plantean dos tipos de análisis jurisprudenciales. El primero de ellos denominado La línea jurisprudencial: análisis dinámico de precedentes y el segundo análisis estático del precedente jurisprudencial; A continuación destacaremos el rasgo más significativo del primero.

\section{La Línea Jurisprudencial: Análisis Dinámico De Precedentes}

\section{(Registro fotográfico 2) ${ }^{2}$}

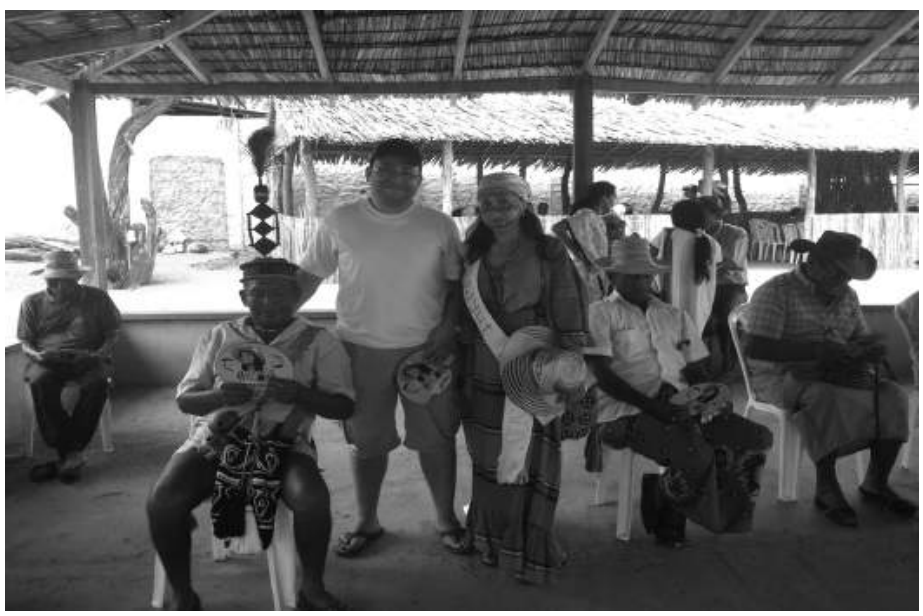

2 Festival Wayuu en Uribia con participación de los palabreros.

El método para la construcción de líneas jurisprudenciales es denominado por el profesor López como: análisis diacrónico y estructural. Cuyos pasos los podemos sintetizar de la siguiente forma:

Como un primer paso, está la formulación del problema jurídico como encabezamiento de la línea. El Problema jurídico es la pregunta que encabeza la línea de jurisprudencia y que el investigador está tratando de resolver mediante la estructuración compleja de varios pronunciamientos judiciales y de la relación de estos con los otros materiales normativos (tales como textos constitucionales y legales). (López, 2000, p 60).

Así mismo, el autor advierte, que no se deben realizar líneas jurisprudenciales conceptualistas, esto es, que un derecho tan general como el 
debido proceso, no debe encabezar una línea jurisprudencial. Esto se refiere a la formulación del problema jurídico. Mucho más adecuado resulta formular problemas jurídicos en los que se mencione algún "derecho", "texto" o "artículo" constitucional pero vinculado con patrones fácticos que traten de reunir los hechos materiales del caso. (López, 2000, p 61).

Una vez se estructure y delimite el problema jurídico como encabezamiento de la línea se procederá a identificar las sentencias relevantes dentro de la línea, para con ello construir teorías estructurales (narraciones creíbles) que permitan establecer la relación entre los pronunciamientos constitucionales. Un cuarto paso es graficar la línea jurisprudencial, lo cual permite identificar patrones de cambio decisional. Como etapa final tenemos la labor de determinar la existencia de un patrón de desarrollo decisional.

De lo anteriormente expuesto se pretende la construcción de una línea jurisprudencial, es decir, la formulación de un problema jurídico, en el cual se identifiquen las sentencias de la Corte Constitucional que resuelven el problema planteado.

\section{Problema jurídico que Encabeza la \\ Línea}

De acuerdo con el objetivo planteado en la investigación, a fin de determinar las tensiones que se suscitan entre los derechos humanos y el derecho propio indígena, hemos procedido a formular el siguiente problema jurídico:

¿Las decisiones adoptadas por las comunidades indígenas en ejercicio de su función jurisdiccional vulneran los derechos fundamentales?

Para resolver esta pregunta graficamos las dos vertientes que surgen de ella. Por una parte señalamos las sentencias en las que la Corte Constitucional considera vulnerados los derechos fundamentales por parte de las autoridades indígenas en ejercicio de su función judicial; en la otra vertiente, se señalan las sentencias en las cuales la Corte Constitucional ha dicho que las decisiones proferidas por la jurisdicción indígena no vulneran los derechos fundamentales de los individuos.

Se destaca que los pronunciamientos de la Corte tienen como origen la interposición de acciones de tutela por parte de miembros de las comunidades indígenas, quienes consideran que las "sentencias"3 indígenas están vulnerando sus derechos individuales fundamentales.

3 La palabra está entre comillas, por cuanto debe ser objeto de estudio determinar si las decisiones con relevancia para el derecho adoptadas por las autoridades tradicionales, se les puede llamar sentencias. El manejo de las categorías deberá realizarse con detenimiento a fin de no caer en los mismos conceptos desarrollados por el derecho nacional (hegemonicouniversal-occidental).

\begin{tabular}{|c|c|}
\hline $\begin{array}{l}\text { Decisiones judiciales proferidas por la } \\
\text { comunidad indígena que vulneran los derechos } \\
\text { fundamentales }\end{array}$ & $\begin{array}{l}\text { Decisiones judiciales proferidas por la } \\
\text { comunidad indígena que no vulneran los } \\
\text { derechos fundamentales }\end{array}$ \\
\hline - Sentencia T - 254 de 1994 (Confiscación) & - Sentencia T - 254 de 1994 (Destierro \\
\hline $\begin{array}{l}\text { - Sentencia T-349 de } 1996 \text { (Principio de } \\
\text { legalidad de la pena) }\end{array}$ & $\begin{array}{l}\text { - Sentencia T } 523 \text { de } 1997 \text { (Debido proceso. } \\
\text { Sanción penal. Fuete) } \\
\text { - Sentencia SU } 518 \text { de } 1998 \text { (Libertad de } \\
\text { Cultos) } \\
\text { - Sentencia T-812 de } 2011 \text { (Non bis in idem) }\end{array}$ \\
\hline
\end{tabular}


La anterior grafica muestra decisiones constitucionales que resuelven el problema jurídico planteado. Hemos tomado estas sentencias por considerarlas de mayor relevancia. Queremos resaltar la posición que tiene la sentencia T-254 de 1994, que como se observa está graficada en los dos vertientes decisionales; esto se debe a su propio contenido. En ella la Corte consideró que la confiscación, como sanción impuesta por las autoridades tradicionales, vulneraba los derechos fundamentales, mientras que el destierro, no atentaba contra ellos.

A continuación esbozaremos los hecho relevantes y la decisión proferida por la Corte en la sentencia T - 523 de 1997.

\section{Sentencia T- 523 de 1997 Magistrado Ponente Carlos Gaviria Díaz - Debido Proceso, Sanción Penal - Fuete}

\section{Hechos Relevantes}

El 19 de agosto de 1996 fue asesinado Marden Arnulfo Betancur, quien se desempeñaba como Alcalde Municipal de Jambaló. Dos días después, los Gobernadores de los cabildos indígenas de la zona del Norte del Cauca acordaron asumir la responsabilidad de "investigar y sancionar a los responsables de este asesinato".

El primer paso fue ordenar la aprehensión de Francisco Gembuel y cinco personas más, a quienes se acusaba de haber propiciado la muerte del alcalde, por haberlo señalado ante la guerrilla como paramilitar, y por haber sostenido públicamente que Marden Betancur estaba conformando una cooperativa rural de seguridad y había malversado fondos públicos. En esa misma fecha se acordó que, una vez capturados, serían trasladados al Municipio de Toribío, para evitar posibles venganzas contra ellos.

Un día después, el actor interpuso acción de tutela contra el Gobernador del cabildo de Jambaló y contra el Presidente de la Asociación de Cabildos Indígenas del Norte del Cauca, con el argumento de que las autoridades indígenas habían desconocido, en la investigación, la circunstancia de que el grupo guerrillero era el culpable del asesinato del Alcalde, pues citaron a la Asamblea para rendir su informe con anterioridad a la publicación del comunicado.
Sostiene, además, que se violó su derecho al debido proceso, en primer lugar, porque las pruebas obtenidas se mantuvieron en secreto y fue imposible controvertirlas; en segundo lugar, porque las personas que realizaron la investigación eran sus adversarios políticos, circunstancia que hace presumir una decisión arbitraria y, en tercer lugar, porque la comunidad indígena no debería ser quien juzgare su conducta porque, en su opinión, no existe tradición ni uso o costumbre relacionada con el juzgamiento del delito de homicidio, puesto que siempre su trámite ha correspondido a la justicia ordinaria, inclusive a instancia y con el apoyo de los Cabildos que no han vacilado en presentar a los indígenas que se ven involucrados en la comisión de tales ilícitos ante la autoridad judicial ordinaria competente.

Finalmente, y después de reunirse para deliberar, la plenaria de la Asamblea decidió que el sindicado era culpable y dio lectura a los castigos: 60 fuetazos (2 por cada cabildo), expulsión, y pérdida del derecho a elegir y ser elegido para cargos públicos y comunitarios. Al momento de proceder a la ejecución de la pena del fuete, los familiares de Francisco Gembuel y algunos miembros del casco urbano iniciaron un gran desorden, circunstancia que llevó al Gobernador de Jambaló a suspender la ejecución de la sanción y posponerla para el 10 de enero de 1997.

El Juzgado Primero Penal Municipal de Santander de Quilichao el 8 de enero de 1997 concedió la tutela al actor. Si bien reconoció la competencia de la comunidad indígena para adelantar el proceso, consideró que el derecho de defensa había sido violado, y las sanciones impuestas ponían en peligro la vida e integridad personal de Francisco Gembuel. Ordenó, en consecuencia, dejar sin efectos el acta № 1 de diciembre 24 de 1996 y reabrir la investigación realizada por las autoridades indígenas, garantizando el debido proceso, el derecho de defensa y los derechos humanos al momento de determinar la pena.

Los argumentos que sustentan su decisión pueden resumirse así:

1. La respuesta de la comunidad en el sentido de no permitirle al demandante ser defendido por un abogado, viola la Convención Americana de Derechos Humanos (art. 8, literales b, c, d, e y f), así como el art. 29, inciso 4 de la Constitución. Este 
derecho no puede ser tenido en cuenta sólo en la jurisdicción ordinaria, sino que también se exige su cumplimiento en las jurisdicciones especiales.

2. El demandante no tuvo la oportunidad de conocer el acervo probatorio, ni de controvertir las acusaciones contra él.

3. La pena que le impuso la comunidad a Francisco Gembuel (60 fuetazos) constituye una práctica de tortura, porque se trata de 'un acto que causa a otro dolor y sufrimiento grave, física y mentalmente, el que se da en razón de un castigo. La tortura, de acuerdo con la sentencia T- 349 de 1996 proferida por la Corte Constitucional, constituye uno de los límites a la autonomía de las comunidades indígenas.

\section{Problema Jurídico}

La Corte introduce el problema esbozando las características particulares de la justicia Paez así:

Para los Paeces no hay nada que la comunidad no sepa. Por ello, su procedimiento, que se origina en el "yacska te' c'indate tenge'a mecue " o "rastro que dejan los mayores", pretende indagar sobre los hechos que rompieron el equilibrio, a través de la palabra de sus miembros. Para que pueda iniciarse, los familiares o el segmento social al que pertenece el afectado deben solicitar al cabildo que adelante la investigación y sancione a los culpables. Este, a su vez, deberá nombrar una comisión investigadora, integrada por personas de prestigio en la comunidad, quien se encargará de determinar las faltas y "encontrar la mentira en la palabra de los acusados".

Lo primero que deberá hacer esta comisión investigadora, es citar a los presuntos autores para que rindan su versión. Si ellos aceptan la responsabilidad, no habrá lugar a otras etapas, si la niegan, continúa la investigación, recogiendo los testimonios de las personas que dicen haber visto o escuchado algo relacionado con el caso, y realizando las visitas a los lugares donde presuntamente ocurrieron los hechos.

Cumplidos estos procedimientos, el siguiente paso será, entonces, la valoración que hace el cabildo del informe presentado por la comisión investigadora. Si se encontró la mentira, se cita a una Asamblea General, que como máxima autoridad deberá fallar, y, si es el caso, imponer las sanciones. En ella se dan a conocer las pruebas, se solicita la confesión pública del acusado y se realizan los careos, es decir, la confrontación de la palabra del sindicado con la de las personas que rindieron testimonios en su contra. Como la Asamblea General es infalible, según sus miembros, - pues sus decisiones están basadas en el "us yacni" (la memoria), que se encuentra a través de un ejercicio colectivo que permite hacer público el suceso oscuro -, no está contemplada la segunda instancia. Es claro que estos sucesos oscuros no solo son aquellos que produjeron directamente el daño, sino también los que de alguna manera hayan permitido o facilitado la alteración de la armonía.

La sanción, por su parte, será la única que podrá restaurar este equilibrio roto. Al ser aplicada públicamente cumple una labor ejemplarizante y preventiva, que busca disuadir a los demás miembros de la comunidad de cometer faltas en el futuro, y al acusado de reincidir.

Los castigos más usuales entre los Paeces son: el fuete, los trabajos forzosos en las empresas comunitarias, las indemnizaciones a las personas o familias de los afectados y la expulsión del territorio. El fuete y el destierro, que son los castigos que interesan en este caso, son ampliamente utilizados en el cabildo de Jambaló. El primero, que consiste en la flagelación corporal con un "perrero de arriar ganado", aun tratándose de una práctica heredada de los españoles, tiene un significado propio: el rayo, que es pensado por los Paeces como mediador entre lo claro y lo oscuro, es decir, como un elemento purificador.

El segundo, por su parte, es el castigo más grave, y sólo se aplica a quienes reinciden en la falta y a los que no aceptan la autoridad del cabildo. "Aunque la imputación de la sanción es personal, existen casos en que se extiende a la familia, por no haber contribuido a detener la infracción". Tal situación se explica porque, en la tradición Páez, una de las responsabilidades principales del núcleo familiar es conocer o controlar lo que hace cada uno de sus miembros.

En cuanto al derecho de defensa, que el actor asume como violado por la negativa de la comunidad de permitirle ser asistido por un abogado, la Corte aclara que, en contra de lo establecido por los jueces de tutela, los medios para ejercer este derecho en los casos que 
adelantan las autoridades indígenas, no tienen que ser aquéllos contemplados por las normas nacionales o los tratados internacionales, sino los que han sido propios dentro del sistema normativo de la comunidad en Jambaló. Por ejemplo, el acusado puede ser defendido por un miembro que conozca la lengua y las costumbres y, además, tiene la oportunidad de hablar personalmente durante la Asamblea, para contradecir a los testigos que declararon en su contra.

Igualmente, en la sentencia mencionada, manifiesta la Corte:

La actitud de los jueces de tutela, al pretender imponer el uso de un abogado en este proceso es, por lo tanto, contraria al principio de diversidad étnica y cultural, pues en una sociedad que reconoce la existencia de diferentes formas de ver el mundo, no es deseable privilegiar las prácticas de una determinada cosmovisión, ni exigir que un grupo humano renuncie a las tradiciones $\mathrm{y}$ valores esenciales para la supervivencia de la cultura que lo caracteriza.

Solución del caso concreto. La Tensión de Derechos

Para la Corte la sanción del fuete, impuesta al actor por la Asamblea General, muestra claramente una tensión entre dos tipos de pensamiento: el de la sociedad mayoritaria y el de la comunidad indígena Páez. En el primero, se castiga porque se cometió un delito, en el segundo se castiga para restablecer el orden de la naturaleza y para disuadir a la comunidad de cometer faltas en el futuro. El primero rechaza las penas corporales por atentar contra la dignidad del hombre, el segundo las considera como un elemento purificador, necesario para que el mismo sujeto, a quien se le imputa la falta, se sienta liberado.

Frente a esta disparidad de visiones, ¿es dable privilegiar la visión mayoritaria? La Corte ya ha respondido este interrogante: No, porque en una sociedad que se dice pluralista ninguna visión del mundo debe primar y menos tratar de imponerse; y en el caso específico de la cosmovisión de los grupos aborígenes, de acuerdo con los preceptos constitucionales, se exige el máximo respeto.
Las únicas restricciones serían, según la Corte, el derecho a la vida, la prohibición de la esclavitud y la prohibición de la tortura. Esta última es la que se entra a analizar en relación con la práctica del fuete, dado que, según los jueces de tutela, es un comportamiento que encuadra dentro de la restricción mencionada.

En relación con las penas corporales que impone una comunidad indígena, la Corte señala que ya existe un antecedente jurisprudencial de esta Corporación. En la sentencia T-349 de 1996, tantas veces citada, se aceptó la práctica del cepo en la comunidad Emberá - Chamí, estableciendo que, lejos de tratarse de un comportamiento cruel e inhumano, se trataba de una pena que hacía parte de su tradición y que la misma comunidad consideraba como valiosa por su alto grado intimidatorio y por su corta duración, consideraciones que bien pueden extenderse a la práctica de fuete dentro de la comunidad Páez.

Para la Corte el fuete consiste en la flagelación con "perrero de arriar ganado", que en este caso se ejecuta en la parte inferior de la pierna. Este castigo, que se considera de menor entidad que el cepo, es una de las sanciones que más utilizan los Paeces. Aunque indudablemente produce aflicción, su finalidad no es causar un sufrimiento excesivo, sino representar el elemento que servirá para purificar al individuo: el rayo. Es pues, una figura simbólica o, en otras palabras, un ritual que utiliza la comunidad para sancionar al individuo y devolver la armonía.

En este caso, y al margen de su significado simbólico, la Corte estima que el sufrimiento que esta pena podría causar al actor, no reviste los niveles de gravedad requeridos para que pueda considerarse como tortura, pues el daño corporal que produce es mínimo. Tampoco podría considerarse como una pena degradante que "humille al individuo groseramente delante de otro o en su mismo fuero interno", porque de acuerdo con los elementos del caso, esta es una práctica que se utiliza normalmente entre los Paeces y cuyo fin no es exponer al individuo al escarmiento público, sino buscar que recupere su lugar en la comunidad.

Visto el anterior análisis, procederemos a exponer los aspectos más generales del trabajo de campo, realizado con la comunidad indígena Wayuu, en el departamento de la Guajira. 


\section{Aspectos Generales Del Trabajo Desarrollado En Campo}

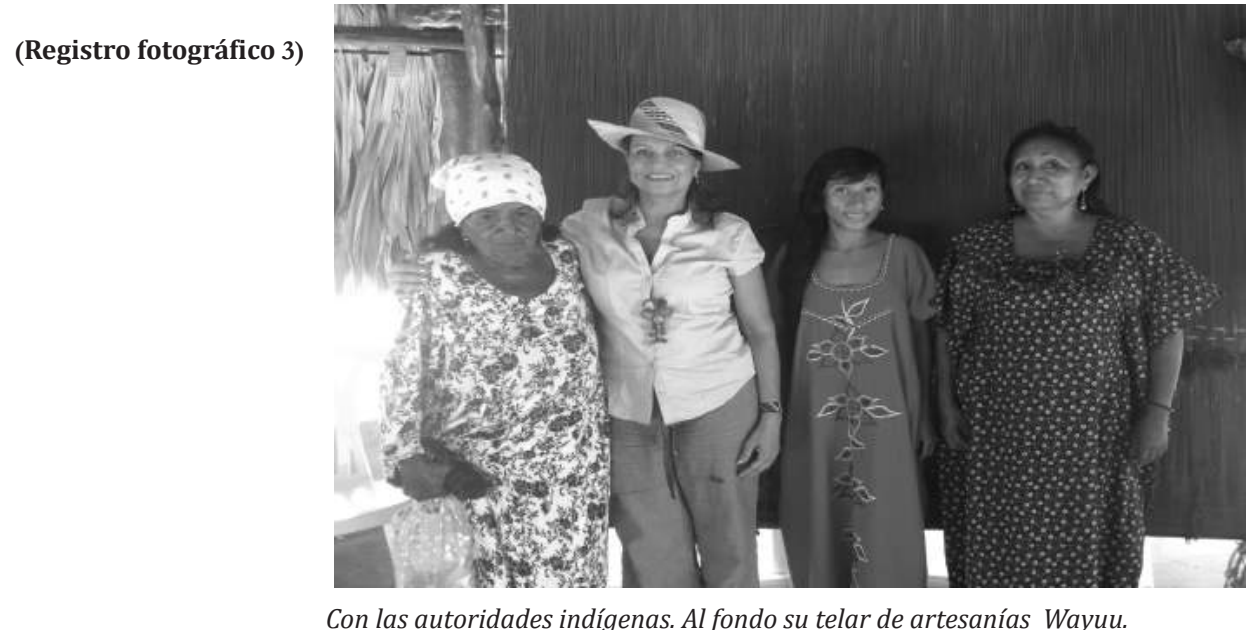

Este trabajo parte de la necesidad de exponer y dar a conocer la información recolectada, para ello se consigna las apreciaciones que se pudieron realizar a través del trabajo de observación, entrevistas y aplicación de encuestas que se realizó en las comunidades indígenas Wayuu.

Departamento: Guajira, Municipio: Riohacha, Rancherías Seleccionadas: La Loma, Irrachon y Palasimana.

Como aspectos generales a tener en cuenta del trabajo desarrollado en campo se consideraron los siguientes: Percepción del derecho indígena wayuu con respecto a la legislación colombiana entre la población consultada; las prácticas culturales con respecto a lo jurídico en el pueblo Wayuu y las decisiones adoptadas por la comunidad Wayuu para la resolución de conflictos, que sobrepasan los límites establecidos por la Constitución a la autonomía indígena.

La población consultada hace parte del municipio de Riohacha, y comprende tres comunidades conocidas como Rancherías en ese orden tenemos: La loma, Irrachon y Palashimana, donde se realizaron entrevistas de tipo grupal, aplicando los instrumentos metodológicos, que se sugieren para este tipo de actividades.

En estas comunidades existe un conocimiento real sobre la coexistencia entre el derecho propio indígena y el nacional dentro de su territorio. Las tensiones que se presentan se dan cuando se desconoce la normatividad existente al interior de las comunidades para la resolución de conflictos de cualquier índole.

De acuerdo a lo expuesto por los integrantes de cada una de estas comunidades, se pueden extraer las siguientes apreciaciones:

\section{Los Conflictos y Faltas en la Comunidad}

El tipo de conflicto que se presenta con mayor frecuencia en las comunidades consultadas es el robo de animales de cría como: Chivos, ovejos o vacas. Esto, según su propia explicación, se debe a que la población ya no es uniforme, hay mucha población fluctuante que no pertenece a la población Wayuu, así como la pérdida gradual de las directrices culturales basadas en la solidaridad y relación armónica con las castas existentes.

Los causantes de los conflictos son sancionados acorde a la característica de la falta cometida, al interior de la comunidad se habla de faltas y no de delitos. La sanción puede ser el pago mediante especies animales como el chivo, el ovejo u otros que la familia del agresor posea. Actualmente es mayor la utilización del dinero como medida de tasación de la sanción.

En años anteriores se impuso la sanción del destierro y se dejaba en manos de la familia agredida al agresor si su comportamiento era reiterativo, para que hiciesen con él lo que considerarán mejor. Aquí se puede observar cómo 
este tipo de sanciones podrían vulnerar derechos fundamentales.

Cuando el comportamiento de algunos de sus miembros se sale de la capacidad de resolución del derecho propio, es decir de la enramada, se recurre a la Secretaria de Asuntos Indígenas Municipal que tiene unos mediadores quienes siempre buscan que los conflictos se manejen y se resuelvan de la mejor manera. Generalmente estos conflictos tienen que ver con homicidios, robo continuo de ganado, o uso de la fuerza por alguna de las dos familias.

Por último, cuando no hay otra vía para resolver un conflicto que involucre muertos o derramamiento de sangre, se forman las llamadas guerras entre clanes; sin embargo, estos casos cada día son menos frecuentes en el pueblo Wayuu debido a que sus miembros sienten aprecio por la vida y la integridad familiar.

Las compensaciones en dinero o especie son proporcionales a la gravedad de la falta. Al homicidio se le llama noutirruy, éste es considerado como una falta grave y la compensación sería mucho mayor que un simple robo.

Las indemnizaciones por cada falta pueden tasarse de la siguiente manera:

a. Homicidio: Collares de tuma (piedras preciosas antiguas), 100 chivos, 10 cabezas de ganado, mula o caballo, si los hay, 100 ovejos, armas, si las hay, y dinero, 20 millones.

b. Robo: Acorde a la cantidad hurtada. Quien es sorprendido en flagrancia fácilmente puede ser muerto por los propietarios de las cosas que se pretenda hurtar.

c. Riñas: Conforme al acto que genere la riña, si hubo derramamiento de sangre la compensación puede ser mayor, generalmente 10 chivos u ovejos.

En cuanto al homicidio es conveniente aclarar que el pago de la compensación asegura que no haya fricciones entre las familias y no se llegue a extremos. Se tiene en cuenta el carácter y comportamiento tanto del homicida como el de la víctima; si en las conversaciones entre los palabreros coinciden en que tanto el homicida como la victima actuaron de mala fe la compensación será equilibrada, si se comprueba que el homicida actuó con sevicia se mantendrá el monto fijado, así a la familia del homicida le parezca demasiado alta.

\section{El Palabrero, Las Figuras de Autoridad y El conocimiento de la Normas}

La persona encargada de dirimir o resolver los conflictos al interior de una comunidad determinada es el palabrero que puede ser a su vez autoridad tradicional como gobernador del cabildo.

El palabrero emerge como la figura central de la justicia Wayuu. Funge como conciliador que acerca a las partes del conflicto, obra en su representación, busca vías de solución e incluso determina los montos de las indemnizaciones que deben ser pagadas por la familia o grupo transgresor.

Este no es elegido por su comunidad, son las mismas circunstancias dadas por los conflictos las que definen quién puede ser el palabrero. Quien asume el papel de palabrero debe reunir ciertos requisitos o condiciones: Debe ser mayor de edad; dominar la lengua; saber explicar y saber darse a entender; ser sereno y dar ejemplo de su comportamiento en la comunidad.

El Palabrero junto con la Autoridad Tradicional y El Gobernador del Cabildo, son figuras de autoridad reconocidas por la comunidad. El Gobernador investido de autoridad no hace parte de la tradición ancestral de los Wayuu. Este concepto fue desarrollado por las Leyes de la Nación. Su presencia ha logrado integrarse a la dinámica actual del discurso reivindicativo de los pueblos indígenas del país.

La Autoridad Ancestral, reconocida y descrita por los entrevistados, es definida como el Alaula (Anciano de la comunidad) quien es el mismo palabrero, o autoridad tradicional, en el contexto actual.

Cuando un conflicto no logra ser resuelto en primera instancia por la autoridad de la enramada, es decir, por el palabrero, y tampoco por la Secretaria de Asuntos Indígenas Municipal, algunos de los involucrados en el conflicto recurren a la Fiscalía. Esto se da más que todo cuando hay un desconocimiento de las normas 
que rigen la cultura, o simplemente cuando se quiere evadir de la responsabilidad pecuniaria que puede acarrear el comportamiento de los agresores.

También se ve como un medio para que su problema sea resuelto, debido a que las anteriores instancias no lo pudieron lograr. Además, en ocasiones, al acudir a la Fiscalía se busca coerción para que se cumpla lo pactado por las partes, para que se paguen indemnizaciones o para evitar las guerras entre clanes.

El conocimiento de las normas que regulan la conducta de los miembros del pueblo Wayuu, en palabras de las tres autoridades presentes en la entrevista, es algo que se da mediante el aprendizaje cotidiano. Esta actividad se basa en las conversaciones de los mayores, donde al niño se le aconseja escuchar cada palabra proferida por las autoridades, él debe estar presente en las reuniones que se organizan para resolver conflictos. Generalmente el Palabrero lleva un acompañante para que vaya aprendiendo sobre los conflictos gestados y la manera de dirimirlos.

La Justicia Propia no es objeto de enseñanza en las escuelas donde se aplica el sistema etnoeducativo. Para los entrevistados existe un distanciamiento entre los contenidos que se imparten en las aulas de clase y las directrices culturales que rigen la vida wayuu, incluyendo el sistema normativo, por lo que proponen que en estas escuelas o colegios, con carácter etnoeducativo, se designen palabreros que se centren en la enseñanza de la justicia propia Wayuu.

\section{Prácticas Culturales de la Justicia propia Wayuu}

Entre las prácticas y costumbres que se aplican en el pueblo wayuu con respecto a lo normativo, tomando como referencia esta muestra de la población representada en tres comunidades, encontramos una preferencia por el uso de la Justicia Wayuu. Esto en cuanto a la aplicación de la normatividad existente, la cual es de uso cotidiano y se practica en todas las comunidades que hay en estos momentos.

Son pocos los conflictos que son llevados a la jurisdicción ordinaria porque se considera que, lejos de resolver los problemas, lo que hace es agudizarlos, presentándose incluso un agravamiento en las relaciones de los miembros de una comunidad sobre la otra. Se garantiza el uso de esta normatividad porque se considera que son la herencia que dejo Maleiwa (Dios) para que sus hijos pudieran reproducirse social y culturalmente a lo largo de los años.

En cuanto a las prácticas culturales de la justicia propia Wayuu encontramos:

a) El uso de la enramada cotidianamente como espacio de recibimiento de visitas y de resolución de conflictos.

b) La conversación de los mayores, ancianos, palabreros y autoridades que los niños escuchan en las comunidades.

c) La narración oral, centrada en consejos para no repetir las experiencias de otras personas. La interpretación de los sueños, que ponen en alerta lo posibles conflictos entre las familias.

d) El uso de la figura del palabrero, como el mediador en la resolución de los conflictos.

e) El reconocimiento de las normas existentes, a través del aprendizaje de generación en generación.

f) La compensación en dinero u especie como forma de subsanar la falta acontecida.

g) La guerra entre familias, si la circunstancia lo amerita.

h) La proporcionalidad existente la tasación de la compensación y la gravedad de la acción realizada.

i) El uso de la lengua Wayuu en las conversaciones de resolución de conflictos; se piensa que quien no la hable no está capacitado para ser palabrero, su palabra pierde fuerza.

j) El uso o acercamiento a las instancias de la justicia arijuna como último recurso.

Entre quienes aportaron con sus voces en la entrevista grupal realizada se encuentran las siguientes autoridades tradicionales:

Remedio López Epiayu (comunidad palashimana); José María Bonivento Sijona (comunidad la loma): Carlos Pushaina (comunidad Irrachon). 


\section{CONCLUSIONES}

\section{Relativas al trabajo de campo. Aportes significativos a la investigación de trabajo de campo}

Del trabajo de campo realizado en las tres rancherías visitadas, incluida la junta de palabreros, de su observación, intercambio y análisis de la información recolectada, podemos extraer las siguientes conclusiones:

Los Indígenas Wayuu no acuden a la justicia ordinaria por desconocimiento y poca efectividad de la misma, por evitar la tramitología, porque no saben leer y escribir, porque les genera pérdida de tiempo y dinero, porque no creen en la justicia blanca, o simplemente desconfían de ella, además se han percatado que al acudir a las instituciones estatales, tales como la fiscalía o la policía, en conflicto suscitado puede, incluso, agravarse.

La Autoridad ancestral reconocida y descrita por los entrevistados, es definida como el Alaula (Anciano de la comunidad), quien es el mismo palabrero o autoridad tradicional en el contexto actual. Este no es elegido por su comunidad, son las mismas circunstancias dadas por los conflictos, las que definen quién puede ser el palabrero. Quien asume el papel de palabrero debe reunir ciertos requisitos o condiciones: debe ser mayor de edad; dominar la lengua; saber explicar y saber darse a entender; ser sereno y dar ejemplo de su comportamiento en la comunidad.

Las personas en general, los adultos mayores, acuden al palabrero y no conocen las instancias y competencias de la justicia ordinaria, por todo lo descrito anteriormente.

El Palabrero es una persona (no siempre son los mayores) distinguida por sus actitudes de conciliador, que son innatas, y la experiencia que adquieren de sus ancestros: padres, abuelos $u$ otros.

Es relevante preguntarnos: ¿Cómo se hace el palabrero? ¿Cuáles son sus características? ¿Y cuál es la fuerza en sus decisiones en la resolución de conflictos? Vemos que no existen condiciones o requisitos para la elección del palabreo, generalmente, son reconocidos por parte de la comunidad, como aquellos que gozan de una mayor elocuencia, de un don para conciliar y para determinar las indemnizaciones frente a cada caso en concreto.

El mayor conflicto que se presenta en las comunidades visitadas es por el robo de animales, le sigue el conflicto entre clanes: llamadas disputas interclaniles.

\section{Relacionadas con las jurisprudencias}

La sentencia T 349 de 1996 de la Corte Constitucional constituye uno de los límites a la autonomía de las comunidades indígenas, en cuanto establece que el fuete es una de las prácticas de tortura porque se trata de un acto que trata dolor y sufrimiento grave, físico y emocional. La justicia ordinaria rechaza las penas corporales por atentar contra la dignidad del hombre, en tanto que algunas comunidades indígenas la consideran como un elemento purificador que libera de la falta al imputado.

La Tutela 380 de 1993 de la Corte Constitucional, conforme al espíritu de protección de la diversidad étnica y cultural, indica que, el derecho a la propiedad de las comunidades indígenas adquiere el carácter de fundamental; y se responde afirmativamente, pues el territorio es de vital importancia para la conservación de su cultura y tradiciones. De aquí surge la regla dogmática que se esboza así: "el derecho de propiedad colectivo de los grupos étnicos tiene carácter fundamental".

El profesor Camilo Borrero ha señalado en su trabajo de jurisprudencial constitucional la siguiente subregla dogmática: Las comunidades indígenas son titulares del derecho fundamental a la subsistencia, del cual se deduce directamente el del derecho a la vida, consagrado en el artículo 11 de la Constitución Política de Colombia.

El principio de la Diversidad étnica y cultural de la nación colombiana se deriva de la aceptación de la existencia de comunidades con raíces ancestrales y formas distintas de concebir la vida y el mundo. Es la base para la aceptación del otro sujeto, bajo el entendido de lo multicultural, dejando atrás el intento de la monoculturización, ya trabajada desde la conquista mediante el repudio de lo distinto.

En estas comunidades existe un conocimiento real sobre la coexistencia entre el derecho propio 
indígena y el nacional dentro de su territorio. Las tensiones que se presentan se dan cuando se desconoce la normatividad existente al interior de las comunidades para la resolución de conflictos de cualquier índole.

Del artículo 246 de la Constitución Política se extraen cuatro elementos centrales de la jurisdicción especial indígena: i) La posibilidad de que existan autoridades judiciales propias de los pueblos indígenas. ii) La potestad de éstos de establecer normas y procedimientos propios. iii) La sujeción de dichas jurisdicción y normas a la Constitución y la ley. iv) La competencia del legislador para señalar la forma de coordinación de la jurisdicción indígena con el sistema judicial nacional.

\section{Relacionadas con las tensiones mismas, respecto a su surgimiento y solución}

Las tensiones que se suscitan entre la jurisdicción nacional y el derecho propio, son generadas por la misma concepción que se tiene respecto de la visión de mundo. Los derechos humanos obedecen a una visión universal, enmarcada en una tradición occidental de carácter liberal, el derecho propio se enmarca en las tradiciones y cosmovisiones de cada comunidad.

La Corte Constitucional ha entendido la importancia de la pluralidad y acepta las formas propias de hacer justicia de los pueblos indígenas, sin embargo, ha dejado claros los límites de esta autonomía, frente a los cuales cualquier decisión de la autoridad tradicional que los sobrepase, sería una decisión contra legem.
Las tensiones entre estas dos formas de administrar justicia, la nacional y la tradicional, plantean nuevamente la necesidad de una ley de coordinación entre la rama judicial y las autoridades indígenas.

Existen muchas debilidades en las autoridades indígenas para resolver los conflictos que se presentan al interior de la comunidad, lo que lleva a sus individuos a acudir a las instituciones nacionales. No existe una política pública de capacitación, fortalecimiento y seguimiento a las autoridades tradicionales. Tampoco hace parte de las escuelas etnoeducativas.

\section{Relacionadas con los Derechos Humanos}

Los derechos humanos imponen los límites mínimos al principio de maximización de la autonomía jurisdiccional indígena, ninguna decisión adoptada por las autoridades tradicionales, puede vulnerar el derecho a la vida, justificar la tortura ni la esclavitud o la servidumbre.

La legalidad mínima, por aplicación constitucional, emanada del Art. 246 de la Constitución Política, es también un límite, y se entiende como la existencia de reglas previas respecto a la autoridad competente, los procedimientos, las conductas y las sanciones, que permitan a los miembros de cada comunidad un mínimo de previsibilidad en cuanto a la actuación de sus autoridades.
- Arbeláez. L. (2004) La Jurisdicción Especial Indígena en Colombia y los Mecanismos de Coordinación con el Sistema Jurídico Nacional. Guatemala. Consejo Superior de la Judicatura.

- Benito. C. (2003) Introducción al Estudio de los Derechos Humanos. Madrid. Editorial Universitas.

- Borrero. C. (2003) Multiculturalismo y Derechos Indígenas. Bogotá, D.C. Ediciones Anthropos Ltda.
- Castro, S. (2002) La poscolonialidad explicada a los niños. Bogotá: Editorial Universidad del Cauca. Instituto pensar, Universidad Javeriana.

- CECOIN y OIA (2008) La Tierra contra la Muerte. Conflictos Territoriales de los Pueblos Indígenas de Colombia. Bogotá, D.C. Ediciones Anthropos.

- CONAIE (2007) Somos Hijos del Sol y de la Tierra Derecho Mayor de los Pueblos Indígenas de la Cuenca Amazónica. Ecuador. Manthra Editores. 
- DANE (2007) Colombia una Nación Multicultural. Bogotá, D.C. Departamento Nacional de Estadística.

- Defensoría del Pueblo. (2001) Derecho Internacional Humanitario. Bogotá

- Defensoría del Pueblo. (2001) Derechos Humanos, Derecho Internacional Humanitario $Y$ Derecho Penal Internacional. Bogotá

- FUNDACIÓN KONRAD ADENAUER (2006) Seminario de Coordinación entre el Derecho Indígena y el Sistema Jurídico Oficial. México. Fundación Konrad Adenauer de México.

- Gómez. H. (2000) De la justicia y el poder indígena. Popayán: Editorial universidad del cauca.

- Londoño. B. (2004) Función Ecológica de la Propiedad en los Resguardos Indígenas de Colombia. Bogotá, D.C. Universidad del Rosario.

- López, D. (2000). El Derecho de los Jueces. Bogotá: Uniandes

- Morales. O. (2007) Derecho Precolombino. Raíz del Nacional y del Continental. Bogotá, D.C. Academia Colombiana de Jurisprudencia.

- Morales. P. (2010) Los Idiomas de la Reetnización. Bogotá, D.C. Universidad Nacional de Colombia.

- O.N.I.C. y C.S.J. (2006) Compilación y Selección de los Fallos y Decisiones de la Jurisprudencia Especial Indígena 1980 2006. Bogotá, D.C. Legis S.A.

- ONIC. (2007) Derechos de los Pueblos Indígenas y Sistemas de Jurisdicción Propia. Bogotá, D.C. Editorial Bochica.

- Paz. E. (2004) Investigación Cualitativa en Investigación. Fundamentos y Tradiciones. Madrid.

- Perafán. C.(1995) Sistemas jurídicos Páez, Kogui, Wayuu y Tule.Bogotá: Colcultura. Instituto Colombiano de Antropología.

- Perafán. C.(1995) Sistemas jurídicos Tukano, Chamí, Guambiano, Sicuani. Bogotá: Colcultura. Instituto Colombiano de Antropología.
- Peréz. J. (2004) Derecho Constitucional Colombiano. Bogotá, D.C. Editorial Temis S.A.

- Amparo. G. (2010) La Consulta Previa con Pueblos Indígenas y Comunidades Afrodescendientes en Colombia. Bogotá, D.C. Universidad del Rosario.

- Ramos G. (2011) Constitución Política de Colombia. Ediciones Nueva Jurídica.

- Rojas, F. (2001). Proyecto deley para la creación de la universidad indígena de Colombia. Bogotá: Senado de la República.

- Sánchez. E. (2002) La Aplicación Práctica de la Política del Reconocimiento a la Diversidad Étnica y Cultural. Bogotá, D.C. Instituto Colombiano de Bienestar Familiar.

- Sánchez. E. (2002) ¿La Cultura como Clonación?Bogotá, D.C. Instituto Colombiano de Bienestar Familiar.

- Solano N. y Sepulveda M. (2008). Metodología de la Investigación Social y Jurídica.

- Sanchez. R. (2010) La Emancipación de los Derechos Humanos. Universidad Nacional.

- Semper, F.(2003) Los Derechos de los pueblos indígenas de Colombia en la jurisprudencia del Corte Constitucional. Hamburgo: Sebra.

- Suescún, A. (1998). Derecho y sociedad en la historia de Colombia. El derecho chibcha siglo IX - XVI. Tunja: Universidad Pedagógica y Tecnológica de Colombia.

- Tenganá. M. (2005) Justicia Comunitaria Indígena: Una Mirada desde la Reivindicación del Pueblo Indígena de los Pastos. Bogotá, D.C. Red de Justicia Comunitaria.

- Constitución Política de Colombia de 1991.

- Sentencias de la Corte Constitucional

- Sentencia T - 254 de 1994. Magistrado Ponente Eduardo Cifuentes.

- Sentencia C- 139 de 1996 Magistrado Ponente. Carlos Gaviria Díaz.

- Sentencia T - 523 de 1997 Magistrado Ponente. Carlos Gaviria Díaz.

- Sentencia SU 510 de 1998. 